\title{
De helaasheid der leeslijsten: over diversiteit in het literatuuronderwijs
}

\author{
Jeroen Dera
}

\begin{abstract}
Hoe divers is het Nederlandse literatuuronderwijs? Uit wetenschappelijk onderzoek blijkt dat er een serieus onevenwicht is tussen mannelijke en vrouwelijke, westerse en niet-westerse, Nederlandse en Vlaamse auteurs in de boekkeuzes die leerlingen maken.
\end{abstract}

Begin 2016 publiceerde Christiaan Weijts een column in NRC Handelsblad die het startschot gaf voor stevige discussies over de leeslijst van leerlingen op middelbare scholen, voornamelijk in de bovenbouw havo en vwo (hoger algemeen voorbereidend onderwijs en voortgezet wetenschappelijk onderwijs).

Weijts had de literatuurlijst van zijn buurmeisje gezien en hekelde de gedateerdheid ervan, inclusief de "belegen aftrekfantasietjes" van de achterhaalde schrijvers die erop prijkten.

"Fuck de literaire canon", riep Weijts uit, om vervolgens te adviseren wat leerlingen dan wel moesten lezen: "Geef ze Gimmick!, Tirza, Joe Speedboot. Geef ze Giph of De helaasheid der dingen."

Je kunt Weijts eenvoudig aanvallen op de merkwaardige kronkel die hij hier maakt. Niet alleen noemt hij titels die gemakkelijk tot de "literaire canon" van de laatste decennia gerekend kunnen worden, hij raadt vooral ook romans aan die stuk voor stuk frequent op literatuurlijsten staan. Intussen is er nog iets anders wat opvalt: alle boeken die Weijts aandraagt, zijn geschreven door witte mannen, en slechts één daarvan komt uit Vlaanderen.

\section{De leeslijst als spiegel en venster}

De roemruchte column van Weijts bevestigt zo het beeld dat de laatste jaren steeds krachtiger naar voren komt uit kritische bespiegelingen over het literaire veld in het Nederlandse taalgebied. Uit het recente proefschrift van Corina Koolen blijkt bijvoorbeeld dat vrouwelijke auteurs systematisch minder gewaardeerd worden dan hun mannelijke collega's, wat zowel tot uiting komt in het koopgedrag van consumenten als in literaire erkenning door critici en jury's. Scheve verhoudingen zijn er ook op het vlak van etniciteit. Zo lieten Timo Koren en Christine Delhaye zien dat Nederlandse uitgevers en andere literaire professionals (waarschijnlijk onbewust) esthetische maatstaven hanteren die het werk van niet-witte schrijvers in de sfeer van identiteitspolitiek plaatsen, in plaats van in het literaire domein.

Ook op het terrein van het literatuuronderwijs zijn er de laatste jaren zorgen geuit over een gebrek aan diversiteit in de aangeboden teksten. Özcan Akyol vreesde in De Nieuwe Revu dat leerlingen met een Surinaamse achtergrond zich nauwelijks zouden herkennen in de Nederlandse schoolcanon. Op het online podium Brainwash pleitte Niña Weijers op haar beurt voor een leeslijst met meer dan alleen dode, witte, mannelijke schrijvers. En tijdens de Dag van de Literatuurkritiek 2018 in de Brakke Grond zei Karin Amatmoekrim genuanceerd:

Ik wil maar stellen dat het niet zo is dat je een diverse of gemengde literatuur moet bieden om de nieuwe generatie Nederlanders aan je te binden. Het is wel zo dat je de aard van literatuur geweld aandoet, als je niet breder kijkt, en niet verder dan je eigen ervaring zoekt. 
Intussen weten we uit onderwijskundig onderzoek dat niet alleen de aard van literatuur geweld wordt aangedaan als een divers perspectief ontbreekt, maar evengoed een grote groep leerlingen. De Amerikaanse hoogleraar Lee Galda stelt dat literatuur in het onderwijs zowel spiegel als venster is: boeken tonen leerlingen hun eigen cultuur en perspectief, maar zijn ook een raam waardoor je naar andere culturen en gezichtspunten kijkt.

Vanuit die gedachte is het belangrijk dat er in het literatuuronderwijs een breedheid aan perspectieven vertegenwoordigd is: niet alleen om het kritisch denken van leerlingen te bevorderen, maar ook om de almaar diversere leerlingenpopulatie voldoende spiegels te bieden.

Dat laatste is ook essentieel in het kader van leesmotivatie. Onderzoek op het terrein van leesbevordering heeft bijvoorbeeld aangetoond dat leerlingen die systematisch niets terugzien van hun eigen achtergrond in teksten, motivatieproblemen kunnen krijgen die de ontwikkeling van hun geletterdheid in de weg staan.

\section{Leeslijsten, literatuurmethodes en leestips}

Het bovenstaande was voor mij als universitair docent en lerarenopleider alle reden om onderzoek te doen naar de diversiteit van het literatuuronderwijs in Nederland. Het Nederlandse onderwijssysteem leent zich daar tegelijkertijd wel en niet goed voor.

Het examenprogramma voor leerlingen in de bovenbouw van havo en vwo schrijft voor dat scholieren voor hun leeslijst acht (havo) of twaalf (vwo) werken moeten selecteren, waarvan er op het vwo drie moeten dateren van voor 1880 . De overheid stelt geen eisen aan de inhoud van die leeslijst, behalve dat het om "literaire" werken moet gaan.

In de praktijk betekent dit dat er een enorme heterogeniteit aan gekozen titels ontstaat - een nadeel als je onderzoek doet, omdat er nauwelijks leerlingen zijn die precies dezelfde leeslijst hebben en de vraag naar de representativiteit dus stevig opspeelt. Die grote heterogeniteit is tegelijkertijd een voordeel: als je maar genoeg leeslijsten verzamelt, zo is de gedachte, dan krijg je zo veel data dat je patronen kunt vaststellen.

Als het gaat om de auteurs die ertoe doen in het Nederlandse literatuuronderwijs, dan is het patroon helder: inderdaad domineert de witte man, meer specifiek de witte man uit Nederland. Vrouwelijke auteurs, schrijvers met een niet-westerse achtergrond en Vlaamse auteurs zijn op scholen minder vertegenwoordigd of zelfs ondervertegenwoordigd. Dat blijkt uit het onderzoeksrapport De praktijk van de leeslijst (2019), dat ik recentelijk publiceerde in samenwerking met Stichting Lezen.

Voor dat onderzoek analyseerde ik de leeslijsten van 1.616 examenkandidaten havo en vwo uit het schooljaar 2017-2018. De leerlingen maakten daarvoor tezamen 15.743 keuzes en lazen in totaal 1.642 unieke titels van 725 auteurs. Een blik op de tien populairste auteurs op die leeslijsten is al veelzeggend: 


\section{Meest gelezen teksten onder examenkandidaten havo/vwo}

$\begin{array}{llll}1 & \text { Tim Krabbé } & \text { Het gouden ei (1984) } & 558 \\ 2 & \text { Harry Mulisch } & \text { De aanslag (1982) } & 411 \\ 3 & \text { Anoniem } & \text { Karel ende Elegast (ca. 1270) } & 403 \\ 4 & \text { Herman Koch } & \text { Het diner (2009) } & 388 \\ 5 & \text { J. Bernlef } & \text { Hersenschimmen (1984) } & 271 \\ 6 & \text { Willem Frederik Hermans } & \text { De donkere kamer van Damokles (1958) } & 267 \\ 7 & \text { Willem } & \text { Van den vos Revnaerde (ca. 1271) } & 252 \\ 8 & \text { Multatuli } & \text { Max Havelaar (1860) } & 245 \\ 9 & \text { Jan Wolkers } & \text { Turks fruit (1969) } & 240 \\ 10 & \text { Annejet van der Zijl } & \text { Sonny boy (2004) } & 222\end{array}$

De enige vrouw in deze koplijst is de hekkensluiter. Auteurs met een niet-westerse achtergrond komen er niet in voor; de hoogst genoteerde schrijver in dat opzicht is Mano Bouzamour op plaats 28. Moderne Vlaamse auteurs ontbreken eveneens.

Ook buiten de tien koplopers is het intussen duidelijk: leerlingen op havo en vwo lezen vooral boeken van Nederlandse mannen met een westerse achtergrond. Onder de 725 gelezen auteurs (anonieme auteurs uit de middeleeuwen niet meegerekend) bevinden zich 443 mannen $(61,1$ procent) en 281 vrouwen (38,8 procent).

Dat is een iets gunstiger verdeling dan we zien in de Nederlandstalige boekproductie, die grofweg $2: 1$ is. Maar dat positieve nieuws is van korte duur als je alle 15.743 titels op de leeslijsten in de berekeningen meeneemt. In dat geval komen 11.412 titels op het conto van mannen ( 76,1 procent) en 3.579 teksten op dat van vrouwen $(23,8$ procent). Die verhouding van grofweg $3: 1$ betekent een ondervertegenwoordiging van vrouwelijke auteurs op de leeslijsten van examenkandidaten.

Hetzelfde mechanisme zien we bij niet-westerse auteurs. Onder de 725 door leerlingen gelezen auteurs bevinden zich 683 westerse schrijvers (94,2 procent) en 42 niet-westerse schrijvers (5,8 procent). Ook hier wordt de verhouding schever wanneer alle items worden meegenomen. In dat geval staan 14.346 titels $(95,7$ procent) van westerse auteurs tegenover 623 titels van niet-westerse auteurs (4,2 procent).

Overigens wordt de verhouding in dit geval minder scheef, wanneer alleen de boekproductie uit de eenentwintigste eeuw als uitgangspunt genomen wordt. Dan staan 6.355 titels van westerse auteurs $(92,3$ procent) tegenover 532 teksten van niet-westerse auteurs $(7,7$ procent). 
Van de 725 door leerlingen gelezen auteurs schrijven er 652 oorspronkelijk in het Nederlands. Vijfenzestig van die auteurs komen uit Vlaanderen (10 procent), versus 587 Nederlandse auteurs ( 90 procent). Binnen het totale aantal leerlingselecties wordt het percentage aan Vlaamse auteurs intussen kleiner: van de 14.600 titels waarvan kon worden vastgesteld of de auteur afkomstig was uit Nederland of Vlaanderen, waren 1.059 teksten Vlaams (7,3 procent).

Het komt er dus op neer dat naarmate er meer leerlingen een boek kiezen, de kans (nog) groter wordt dat er een boek van een witte man uit Nederland op de leeslijst terechtkomt. Hoe komt dat? Veel leerlingen laten zich voor hun boekkeuzes informeren door hun docenten Nederlands, door de gebruikte lesmethode en door websites als scholieren.com en lezenvoordelijst.nl. De Lezeres des Vaderlands liet al eens zien dat Lezen voor de lijst gedomineerd wordt door mannelijke schrijvers. Zelf deed ik onlangs onderzoek naar de inhoud van drie veel gebruikte methodes voor literatuuronderwijs in Nederland: Laagland, literatuur \& lezer; Literatuur: geschiedenis en theorie en Nieuw Nederlands Literatuur.

De tien meest genoemde auteurs in die drie methodes samen zijn louter Nederlandse mannen met een westerse achtergrond: Harry Mulisch (81 keer genoemd), Willem Frederik Hermans (50 keer), Ferdinand Bordewijk (42), P.C. Hooft (42), Gerard Reve (37), Louis Couperus (35), Hendrik Marsman (35), G.A. Bredero (33), Arnon Grunberg (33) en Multatuli (33). De cijfers per lesmethode spreken verder boekdelen:

\begin{tabular}{|c|c|c|c|}
\hline Lesmethode & & & \\
\hline Laagland, literatuur \& lezer & $91.3 \% \operatorname{man}$ & $97.8 \%$ westers & $67.8 \%$ Nederlands \\
\hline (183 auteurs genoemd) & $8.7 \%$ vrouw & $2.2 \%$ niet-westers & $5.5 \%$ Vlaams \\
\hline Literatuur: geschiedenis en theorie & $88.2 \% \operatorname{man}$ & $98.8 \%$ westers & $45.9 \%$ Nederlands \\
\hline (405 auteurs genoemd) & $11.8 \%$ vrouw & $1.2 \%$ niet-westers & 2.7\% Vlaams \\
\hline Nieuw Nederlands literatuur & $73.6 \% \operatorname{man}$ & $94.0 \%$ westers & $66.9 \%$ Nederlands \\
\hline (284 auteurs genoemd) & $26.4 \%$ vrouw & $6.0 \%$ niet-westers & $8.5 \%$ Vlaams \\
\hline
\end{tabular}

Bemoedigend is hier dat de meest recente lesmethode, Nieuw Nederlands Literatuur, veel gunstiger percentages laat zien dan de andere twee methodes, die echter vaker in het onderwijs worden gebruikt. En in het geval van lesmethodes moet natuurlijk ook aangetekend worden dat ze nu eenmaal een overzicht van de literatuurgeschiedenis moeten geven, terwijl het literair-historische standaardverhaal nu niet bepaald uitblinkt in diversiteit.

Toch is het tekenend dat lesboeken zo'n disbalans laten zien op het vlak van gender, etniciteit en nationaliteit: ze vormen daarmee de neerslag van een breder probleem in het Nederlandse literaire veld.

Hoezeer geschikte literatuur in het Nederlandse literatuuronderwijs onbewust in verband wordt gebracht met witte, mannelijke schrijvers, blijkt uit de leesadviezen die eerstegraadsdocenten Nederlands naar eigen zeggen aan leerlingen geven. Ik vroeg 104 leraren die lesgeven in de bovenbouw om acht titels door te geven die zij regelmatig aanraden 
aan leerlingen in de vierde klas, waar de meesten van hen kennismaken met literatuur. De volgende tien titels werden daarbij het vaakst genoemd:

\begin{tabular}{|c|c|c|c|}
\hline \multicolumn{4}{|c|}{ Meest aangeraden boektitels door eerstegraads docenten Nederlands } \\
\hline 1. & Hanna Bervoets & Alles wat er was (2013) & $31 \mathrm{x}$ \\
\hline 2. & Stefan Brijs & De engelenmaker (2005) & $28 x$ \\
\hline 3. & Harry Mulisch & De aanslag (1981) & $21 \mathrm{x}$ \\
\hline & Thomas Olde Heuvelt & $\operatorname{Hex}(2013)$ & $20 x$ \\
\hline & Lize Spit & Het smelt (2015) & $20 x$ \\
\hline & Mane Bouzamour & De belofte van Pisa (2013) & $19 x$ \\
\hline & Herman Koch & Het diner (2009) & $19 x$ \\
\hline & Kim van Kooten & Lieveling (2015) & $18 x$ \\
\hline & Tommy Wieringa & Joe Speedboot (2006) & $18 \mathrm{x}$ \\
\hline 10 & J. Bernlef & Hersenschimmen (1984) & $16 \mathrm{x}$ \\
\hline
\end{tabular}

Het beeld is hier op het eerste gezicht optimistischer dan in de tabel met meest gelezen titels onder leerlingen. Daar was een vrouwelijke auteur de hekkensluiter, hier is ze koploper en wordt ze in de top tien door twee andere vrouwen vergezeld. Met Bouzamour staat er ook een schrijver met een niet-westerse achtergrond in de top tien, en Vlaanderen is met Brijs en Spit tweemaal in de top vijf vertegenwoordigd. Intussen zijn het ook in deze ranglijst de mannelijke Nederlanders met een westerse achtergrond die eruit springen.

Dat wordt onderstreept als we ons concentreren op de 829 titels die de docenten gezamenlijk doorgaven. We zien dan de inmiddels bekende tendens. Van de 801 titels waarvan het auteursgender bekend is, werd 69,6 procent door een man geschreven en 28,7 procent door een vrouw (de resterende 1,7 procent betrof een auteursduo bestaande uit een man en een vrouw). Tegenover 93,7 procent auteurs met een westerse achtergrond bestond 6,3 procent van de aanraders uit boeken van niet-westerse auteurs. Vlaamse auteurs moesten het doen met 12,8 procent van de leestips, tegenover 87,2 procent voor Nederlandse auteurs.

\section{De klas in}

Er is meer onderzoek nodig om een correlatie aan te tonen tussen docentadviezen en leerlingkeuzes, maar ik durf op zijn minst de hypothese te formuleren dat een diversere leeslijst kan worden bereikt als docenten gemiddeld meer oog hebben voor diversiteit in de adviezen die zij leerlingen geven.

Ook zouden educatieve uitgeverijen wat dat betreft kritisch kunnen kijken naar de lesmethodes die zij op de markt brengen - óók naar het literair-historische gedeelte, waarin Vondel niet door Catherina Lescailje wordt geflankeerd en Hélène Swarth systematisch minder aandacht krijgt dan Willem Kloos.

Het onderzoek dat ik de laatste twee jaar deed naar het Nederlandse literatuuronderwijs, onderschrijft de zorgen die bijvoorbeeld Akyol en Weijers al uitten: er is sprake van een serieuze disbalans tussen mannelijke en vrouwelijke, westerse en niet-westerse, Nederlandse 
en Vlaamse auteurs in de boekkeuzes die leerlingen maken. Uiteraard heeft die constatering slechts betrekking op de buitenkant van het literatuuronderwijs. Het lezen van een boek van een niet-westerse auteur hoeft helemaal niet te betekenen dat er voor een leerling een venster opengaat, en bovendien zou je het oeuvre van zulke auteurs geweld aandoen door te suggereren dat zij boeken over culturele diversiteit schrijven, omdat ze toevallig een nietwesterse achtergrond hebben.

Andersom kunnen ook werken van witte mannen aanleiding geven tot gesprekken over diversiteit - Max Havelaar is een welhaast clichématig voorbeeld. Docenten die leerlingen bewust willen maken van seksisme en racisme zouden dat uitstekend aan de hand van Het gouden ei van Tim Krabbé kunnen doen, de meest gelezen tekst onder examenkandidaten: zowel het personage Rex Hofman als Raymond Lemorne kijkt zeer seksistisch naar vrouwen en bij het beruchte tankstation waar Saskia wordt ontvoerd, loopt nota bene "een neger in een Afrikaanse jurk". De cijfers alleen geven kortom geen compleet beeld als het om diversiteit binnen het literatuuronderwijs gaat, maar ze wijzen wel degelijk op hiërarchieën die juist in het onderwijs doorbroken zouden moeten worden.

Docenten kunnen bijdragen aan een meer inclusief curriculum door te reflecteren op het beeld van schrijverschap dat zij via hun tekstselecties en leestips doorgeven. In mijn colleges op de Nijmeegse lerarenopleiding roep ik startende docenten op om na te gaan hoe groot het aandeel vrouwelijke, niet-westerse en Vlaamse auteurs in hun literatuuronderwijs is - zulke bewustwording is een eerste stap op weg naar verandering. Ook leerlingen zelf moeten daarbij betrokken worden, bijvoorbeeld door ze in de klas de diversiteit van hun eigen leeslijst in kaart te laten brengen - wat ook een mooi startpunt kan zijn voor algemenere discussies over diversiteit in de literaire wereld.

Los van die reflecties zijn er tal van initiatieven die erom schreeuwen hun weg naar de klas te vinden. De Amsterdamse hoogleraar Michiel van Kempen gaf eind 2019 al een belangrijke voorzet door een schooleditie van Albert Helmans De stille plantage (1931) te publiceren. Docenten kunnen echter ook inspiratie putten uit recente bloemlezingen als Zwart (2018), HARDOP (2019) en De nieuwe feministische leeslijst (2019). Daarnaast verdient het aanbeveling om lesmateriaal voor het Nederlandse onderwijs te ontwikkelen dat zich richt op de Vlaamse literaire canon - inclusief de felle discussie over de racistische en seksistische tendensen in Jef Geeraerts' Gangreen 1: Black Venus (1967).

We moeten dus ook in het onderwijs de veelkleurigheid van de literatuur thematiseren - zeker nu de cijfers uitwijzen dat leerlingen bovengemiddeld vaak geconfronteerd worden met de denkwereld van witte mannen uit Nederland. Met Gimmick!, Tirza, Joe Speedboot en Giph kortom - en soms met De helaasheid der dingen. 


\section{Bibliografie}

- Özcan Akyol, 'Liever Amatmoekrim dan de avonturen van Adelbrecht', Nieuwe Revu, 22 januari 2016

- Karin Amatmoekrim, 'Dag van de literatuurkritiek 2018', DeBuren.eu, 21 december 2018

- Jeroen Dera, De praktijk van de leeslijst: een onderzoek naar de inhoud en waardering van literatuurlijsten voor het schoolvak Nederlands op havo en vwo, Stichting Lezen, Amsterdam, 2019

- Jeroen Dera, 'Het begrip 'literatuur' binnen het literatuuronderwijs'. In: G. Rijlaarsdam (red.), Didactiek Nederlands: Handboek. s:i: Levende Talen, 2020

- Jeroen Dera, 'The Cultural Diversity of Text Selections in Dutch Literature Education: An Analysis of Reading Advices, Literature Textbooks and Student Choices'. DOI 10.31234/osf.io/a9tuq

- Jeroen Dera \& Nils Lommerde, 'Persoonlijke voorkeuren, canonieke werken en leesadviezen: Literatuur volgens leraren Nederlands in opleiding'. In: Levende Talen Tijdschrift 21 (2020), 2, pp. 35-39

- Lee Galda, 'Mirrors and windows: Reading as transformation'. In: T.E. Raphael \& K.H. Au (red.), Literature-based instruction: Reshaping the curriculum, Christopher-Gordon, Norwood, 1998, pp. 1-11

- Corina Koolen, Reading beyond the Female: The Relationship between Perception of Author Gender and Literary Quality, University of Amsterdam, 2018

- Timo Koren \& Christine Delhaye, 'Depoliticising literature, politicizing diversity: ethnoracial boundaries in Dutch literary professionals' aesthetic repertoires', Identities 26 (2019), 2, pp. 184-202

- Oberon, Lees- en literatuuronderwijs in havo/vwo, Stichting Lezen, Amsterdam, 2016

- Niña Weijers, 'Tijd voor een leeslijst met meer dan alleen dode, witte, mannelijke schrijvers', Brainwash.nl, 30 januari 2019 